\title{
Oceanography and Marine Biology: An Introduction to Marine Science
}

By David W. Townsend. 2012. Sinauer Associates, 23 Plumtree Road, Sunderland, Massachusetts 01375 USA. 512 pages + appendixes. 139.95 USD. Cloth [and available as an eBook].

David Townsend's Oceanography and Marine Biology originated in a class he has taught at the University of Maine since 1997. It is intended to present an account of the whole breadth of the marine sciences to undergraduate students, aiming at showing them, as he says, "the oceanographic foundation upon which life in the sea depends." How successful is he, and is his book relevant to the general reader?

During the past quarter century the marine sciences have become increasingly quantitative, the most marked split being between biological oceanography, which has cast its lot with physical oceanography and the mathematical approach to biological problems of the sea, and marine biology, which retains some of its natural history flavor but has increasingly created links with quantitative and theoretical ecology. These are not easy bedfellows, or to use another analogy, Townsend may be attempting to mix the immiscible.

In an attractive large-page format, with the use of abundant, often outstanding, illustrations, Townsend deals briefly with the historical background of the marine sciences, then with the scientific method, the origin of Earth and oceans, the formation and evolution of the seafloor, chemical and physical properties of water, atmospheric circulation and its relation to ocean currents, waves and tides, and the general nature of life in the sea. He includes the importance of photosynthetic processes, nutrients and limiting factors, material cycles (notably of nitrogen and phosphorus), vertical circulation and its importance in limiting production, and environmental factors limiting the distribution of marine organisms. He then deals in some detail with the phytoplankton and other primary producers, the zooplankton, with marine benthic (bottomdwelling) and nektonic (swimming) invertebrates, and with fish. Marine ecology gets its due in a chapter on marine environments dealing with subjects such as the intertidal zone, estuaries, salt marshes, mangrove for ests, coral reefs, and the deep ocean. The concluding chapters survey marine vertebrates other than fishes, marine fisheries and aquaculture, and human impacts on the oceans, including global warming. Finally, in three interesting appendixes, he deals with the use of satellites for remote sensing, the climatic implications of El Niño and La Niña phenomena, and techniques for exploring the deep sea. There is an extensive and helpful glossary.

The foundation that gives this book unity is its concentration on the sea as a physical, chemical and biological environment. Nearly all the science is up to date and it represents the range of research on the oceans and the knowledge that results from it in a very creditable and useful way. This is not to say that all is well. Townsend's introductory chapter on the history of the marine sciences is perfunctory, based on dated or questionable sources not on recent scholarship, and trots out some old and discredited warhorses (including the myth of the Portuguese, Henry "The Navigator"). There are apparently inadvertent lapses, such as the reversal of the definitions of Eulerian and Lagrangian methods in physical oceanography (page 188) and an incorrect caption showing recent and historical ranges of sea otters (page 434). Each chapter has a brief, and generally very useful, reading list, allowing the reader to find a way into the broader literature, but the occasional list, such as that on the deep sea, omits important recent references that could provide better guidance to the reader. These should be easy to correct or modify in new editions, or especially in the eBook version available now.

In answer to my introductory questions, this book presents the marine sciences in a compelling and authoritative way. It can be an important resource to the general reader looking for an attractively-presented introduction to the marine sciences, to the teacher of secondary or undergraduate-level oceanography, and to the professional looking for up to date surveys of topics in oceanography and marine biology. It is worth browsing for the quality of the illustrations alone.

ERIC L. MILLS

Department of Oceanography, Dalhousie University, 1355 Oxford Street, P.O. Box 15000, Halifax, Nova Scotia B3H 4R2 Canada 